\title{
Comparison of sea-ice thickness measurements under summer and winter conditions in the Arctic using a small electromagnetic induction device
}

\author{
Christian Haas*, Sebastian Gerland ${ }^{\ddagger}$, \\ Hajo Eicken*, and Heinz Miller*
}

\begin{abstract}
A BSTRACT
D rillhole-determined sea-ice thickness was compared with values derived remotely using a portable smalloffset loop-loop steady state electromagnetic (EM) induction device during expeditions to Fram Strait and the Siberian A rctic, under typical winter and summer conditions. Simple empirical transformation equations are derived to convert measured apparent conductivity into ice thickness. D espite the extreme seasonal differences in sea-ice properties as revealed by ice core analysis, the transformation equations vary little for winter and summer. Thus, the EM induction technique operated on the ice surface in the horizontal dipole mode yields accurate results within 5 to $10 \%$ of the drillhole determined thickness over level ice in both seasons.
\end{abstract}

The robustness of the induction method with respect to seasonal extremes is attributed to the low salinity of brine or meltwater filling the extensive pore space in summer. Thus, the average bulk ice conductivity for summer multiyear sea ice derived according to A rchie's law amounts to $23 \mathrm{mS} / \mathrm{m}$ compared to $3 \mathrm{mS} / \mathrm{m}$ for winter conditions. These mean conductivities cause only minor differences in the $\mathrm{EM}$ response, as is shown by means of 1-D modeling.

H owever, under summer conditions the range of ice conductivities is wider. A long with the widespread occurrence of surface melt ponds and freshwater lenses underneath the ice, this causes greater scatter in the apparent conductivity/ice thickness relation. This can result in higher deviations between EM-derived and drillhole determined thicknesses in summer than in winter.

\section{INTR ODUCTION}

The sea-ice thickness distribution in the polar regions has been shown to respond sensitively to global climate change (M itchell et al., 1990). It is one of the key factors controlling the exchange of energy and momentum between atmosphere and ocean. Therefore, there has been much effort in the past to investigate and develop techniques to measure sea-ice thickness on regional scales. So far, apart from submarine sonar measurements of ice draft (e.g., Wadhams et al., 1992) the most promising technique for large-scale ice thickness determination seems to be airborne low-frequency electromagnetic (E M ) induction (e.g., Kovacs et al., 1987; K ovacs and H olladay, 1990; M ultala et al., 1995). In those studies, E M sounding systems were suspended below a helicopter or built into a fixed-wing aircraft, and measurements were performed in system heights of 15 to $20 \mathrm{~m}$ above the ice surface. The results indicated that the thickness of level portion sof sea ice can be estimated within $5 \%$ of drillhole determined ice thickness. In contrast, over deformed ice, e.g., in the vicinity of pressure ridges, results are not reliable. There, large deviations are a result of the variability within the footprint of the instruments, which is the area in which the secondary field is predominantly generated by induced currents and in which the ice thickness therefore is averaged. Kovacs et al. (1995) estimate the footprint size for vertical coaxial coil arrangements to be about 1.3 times the antenna height above the sea-ice/water interface, and 3.8 times for horizontal coplanar systems. Liu and Becker (1990) and Liu et al. (1991) numerically modeled the E M response over ice keels and developed algorithms to invert it into ice-keel shape, but these approaches are only of limited practical use because the structure of pressure ridges usually is too complex to be inverted realistically. 
B ased on earlier work by Sinha (1976) and H oekstra (1980), Kovacs and M orey (1991) performed ground-based measurements using a small portable steady-state induction device with coplanar coil arrangement to supplement airborne surveys. The instrument used was operated in the horizontal dipole mode and yielded reliable results within $\pm 10 \%$ of the true ice thickness over level ice in the thickness range from 0.7 to $3.5 \mathrm{~m}$, using only the quadrature component of the received secondary field. Compared with airborne measurements, this technique was easy to use, and the lateral resolution of thickness variations was 3 to $4 \mathrm{~m}$, much better than for the airborne systems.

A II the above studies were performed in the A merican sector of the A rctic and in the Baltic Sea, respectively, during winter and spring only. Because of its high resistivity, the ice is considered transparent for EM systems under these conditions. The conductivity of the seawater has to be assumed or is inverted from multifrequency soundings. Kovacs and M orey (1991) showed that small variations in ice and seawater conductivity do not alter the $\mathrm{EM}$ response significantly with respect to ice thickness inversion.

In this paper, we extend the application of EM sea-ice thicknessmeasurementsemploying ground-based small-offset, loop-loop surveys to winter as well as summer conditions in different regions of the A rctic, using the technique of Kovacs and Morey (1991), and then compare them with drilling results. $B$ ased on ice-core analyses, conductivities of A rctic summer sea ice are determined. Then, by means of 1-D modeling of the $\mathrm{E} M$ response, it is examined to what extent the response is altered under summer conditions, when the ice is highly porous and contains a significant meltwater component. Particular attention is focused on special features occurring only in summer, such as surface melt ponds and meltwater lenses at the ice/water interface, because at least the former usually cover between 10 and $50 \%$ of the surface of A rctic summer sea ice (M aykut, 1986). A Ithough ground-based measurements may not be adequate to measure ice-thickness distributions on regional scales, the findings from our applications of the $E M$ method under summer conditions should be of great importance for the suitability of airborne surveys during the melt season as well.

\section{STU DY AREAS}

E M measurements were performed as part of sea-ice research programs conducted during a winter cruise and two summer cruises of the icebreaking research vessel Polarstern, which led to Fram Strait and to the Siberian A rctic, respectively (Figure 1).

The study area in the L aptev Sea is representative of ice conditions prevailing over the vast $E$ urasian shelves, from where first-year ice is exported into the A rctic B asin and after a period of a few years' transport in the Transpolar D rift is finally exported through Fram Strait. Thus, the areas studied represent the two "end-members" of A rctic sea ice, the thinner, young ice of the shelf seas and the aged, deformed multiyear ice in the ablation zone.

Conditions in winter ( $M$ arch 1993) were characterized by very low air temperatures $\left(-40\right.$ to $\left.-33^{\circ} \mathrm{C}\right)$. Profiling was carried out on a snow-covered multiyear floe. The summer measurements (A ugust-September 1993 and 1995) took place during warmer conditions al ways close below $0^{\circ} \mathrm{C}$. H ere, both multiyear and first-year ice, lacking a snow cover and exhibiting extensive development of surface melt ponds, were investigated.

\section{MEA SURE MENTS}

\section{E M system}

A II EM measurements were performed with a standard G eonicsE M 31. This is a portable small-offset loop-loop steadystate induction device with a spacing $r$ of $3.66 \mathrm{~m}$ between small transmitting and receiving coplanar antenna coils of $0.05 \mathrm{~m}$ diameter, forming good approximations of magnetic dipoles. The operating frequency $f$ is $9.8 \mathrm{kHz}$. The instrument yields measurements of apparent conductivity $\sigma_{a}$, which is calibrated from the quadrature phase component of the ratio of the secondary and primary electromagnetic fields $H_{s}$ and $H_{p}$ as

$$
\sigma_{a}=\frac{4}{\omega \mu_{0} r^{2}} \operatorname{Im}\left(\frac{H_{s}}{H_{p}}\right),
$$

where $\omega$ is the angular frequency $(=2 \pi f)$ and $\mu_{0}=4 \pi \times$ $10^{-7} \mathrm{H} / \mathrm{m}$ is the magnetic permeability of free space. The indicated apparent conductivity is a measure of the integrated electrical conductivity of the half-space beneath the instrument.

The primary field generated by the transmitter coil induces eddy currents within the conductive subsurface. The resulting secondary $\mathrm{EM}$ field is measured, through compensation of the primary field, by the receiving coil. The magnitude of the secondary field is proportional to the distance between the coils and the subsurface and its conductivity (Keller and Frischknecht, 1966). In the case of sea ice with its low conductivity, the secondary field is induced mainly in the highly conductive ocean water. The salinity of A rctic seawater typically varies between 30 and 35\% (e.g., Coachman and A agaard, 1974), with temperatures between 0 and $-1.8^{\circ} \mathrm{C}$ resulting in a conductivity between 2300 to $2900 \mathrm{mS} / \mathrm{m}$ (U NE SC O, 1983).

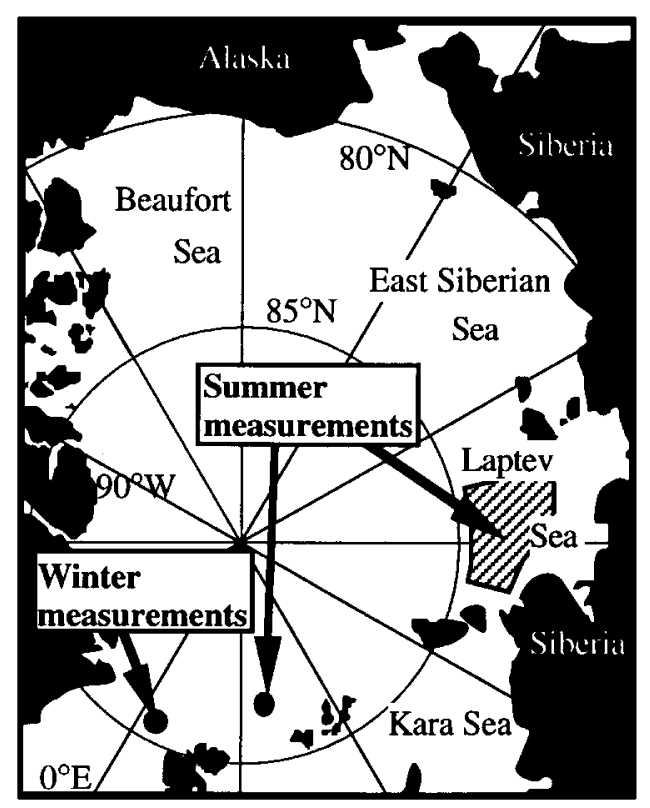

FIG. 1. M ap of the A rctic O cean showing the study regions in the Fram Strait and in the Laptev Sea. 
Therefore, the strength of the secondary field is related directly to the distance between instrument and seawater, or to the sum of sea-ice thickness and (known) instrument height above the ice surface.

\section{Field procedures}

A II profiles used a $4 \mathrm{~m}$ point spacing and were 100 to $250 \mathrm{~m}$ long (Table 1). A t each point, the E M measurements were performed with the instrument placed directly on the snow/ice or melt pond surface and operating in the horizontal dipole mode, i.e., the coil planes were aligned vertically. This mode yields the most accurate interpretations (Kovacs and M orey, 1991) that is mainly a result of the smaller footprint size compared with measurements in the vertical dipole mode (Kovacs et al., 1995; see also in the Introduction).

In addition to the along-profile measurements, a number of individual surface melt ponds were cross-profiled with point spacings varying from 1 to $5 \mathrm{~m}$. M elt ponds typically are some meters to a few tens of meters in diameter and 0.2 to $0.4 \mathrm{~m}$ deep.

D irect measurements of snow depth, ice thickness, and freeboard were conducted in holes drilled at $4 \mathrm{~m}$ spacing. I $\mathrm{n}$ addition, one or several ice cores were taken along each profile for temperature measurements and analysis of ice microstructure and physical properties including ice conductivity (for details of ice-core analysis, see $E$ icken et al., 1995).

In total, EM and direct measurements were performed at roughly 400 single points along 12 standard profiles during both expeditions and additional melt-pond cross-profiles.

\section{1-D modeling}

To examine the influence of different conductivities of winter and summer sea ice as derived by the ice-core analyses on the electromagnetically measured apparent conductivity, 1-D modeling of the $\mathrm{EM}$ response (quadrature component of the relative secondary field) to changing total ice thickness and changing ice conductivity was performed. Full solution formulas for this are given, e.g., by Ward and Hohmann (1988)

Table 1. Mean EM and drillhole derived ice thickness $\overline{\mathbf{z}}_{i_{\mathrm{EM}}}, \overline{\mathbf{z}}_{i_{\text {drill }}}$ and their standard deviations $\mathbf{s}$ and the deviation $\delta=\left(\overline{\mathbf{z}}_{i_{\mathrm{E} \mathrm{M}}}-\overline{\mathbf{z}}_{i_{\text {drill }}}\right) / \overline{\mathbf{z}}_{i \text { drill }} \times 100$ for each single profile.

\begin{tabular}{|c|c|c|c|c|c|c|}
\hline Profile & $\begin{array}{l}\text { L ength } \\
\text { (m) }\end{array}$ & $\begin{array}{l}\bar{z}_{i_{\mathrm{EM}}} \\
(\mathrm{m})\end{array}$ & $s_{\mathrm{EM}}$ & $\begin{array}{l}\bar{z}_{i_{\text {drill }}} \\
(\mathrm{m})\end{array}$ & $S_{\text {drill }}$ & $\begin{array}{c}\delta \\
(\%)\end{array}$ \\
\hline W 1 & 204 & 2.85 & 0.66 & 2.81 & 0.59 & 1. \\
\hline $\begin{array}{l}\text { S1 } \\
\text { S2 } \\
\text { S3 } \\
\text { S4 } \\
\text { S5 } \\
\text { S6 } \\
\text { S7 } \\
\text { S8 } \\
\text { S9 } \\
\text { S10 } \\
\text { S11 }\end{array}$ & $\begin{array}{c}122 \\
100 \\
100 \\
100 \\
100 \\
48 \\
100 \\
100 \\
100 \\
122 \\
100\end{array}$ & $\begin{array}{l}3.25 \\
0.74 \\
1.66 \\
1.79 \\
1.83 \\
1.74 \\
1.85 \\
2.38 \\
1.95 \\
2.56 \\
2.97\end{array}$ & $\begin{array}{l}1.17 \\
0.26 \\
0.63 \\
0.42 \\
0.27 \\
0.06 \\
0.30 \\
0.36 \\
0.55 \\
1.30 \\
0.66\end{array}$ & $\begin{array}{l}3.05 \\
0.78 \\
1.65 \\
1.80 \\
1.84 \\
1.70 \\
1.89 \\
2.37 \\
1.96 \\
2.37 \\
3.12\end{array}$ & $\begin{array}{l}1.08 \\
0.28 \\
0.71 \\
0.60 \\
0.37 \\
0.04 \\
0.32 \\
0.45 \\
0.51 \\
1.07 \\
0.60\end{array}$ & $\begin{array}{r}6 . \\
-5 . \\
0 . \\
-0 . \\
-0 . \\
2 . \\
-2 . \\
0 . \\
-0 . \\
8 . \\
-4 .\end{array}$ \\
\hline A II (Summer) & 1092 & 2.07 & 0.93 & 2.08 & 0.91 & -0.5 \\
\hline
\end{tabular}

and were programmed using a digital filter method (A nderson, 1979). For the modeling, we assumed a seawater conductivity of $2600 \mathrm{mS} / \mathrm{m}$ being a mean surface-water value measured by CTD casts onboard RV Polarstern during the summer cruises (Schauer, pers. comm.) and a coil height of $0.14 \mathrm{~m}$ above the snow/ice surface.

\section{RESU LTS}

\section{C onductivity-thickness transformation}

A s a data example, in Figure 2 an apparent conductivity profile is compared with drillhole determined ice thickness (in the following, total ice thickness, i.e., ice and snow thickness, is referred to as ice thickness) along the same profile. A strong negative correlation between apparent conductivity and ice thickness is obvious.

Plotting apparent conductivity versus ice thickness for all individual measurements establishes a strong negative exponential relationship (Figure 3). By fitting exponential functions to these data, transformation equations are obtained for the conversion of apparent conductivity $\sigma_{a}(\mathrm{mS} / \mathrm{m})$ to ice thickness $z_{i}(\mathrm{~m})$. D ifferent transformation formulas were obtained for the winter and summer data sets (Figure 3).

The fits

$$
\sigma_{a_{w}}=95.8+1095.5 \exp \left(-0.995 z_{i_{w}}\right)
$$

and

$$
\sigma_{a_{S}}=57.2+1270.9 \exp \left(-0.900 z_{i_{S}}\right),
$$

where indices $w$ and $s$ indicate winter and summer data, respectively, explain $91 \%$ (winter) and $98 \%$ (summer) of the total variance in the data. A $n$ estimate of the relative variance $s^{2}$ of the measurements can be gathered by means of Chi-square statistics, since $\chi^{2}$ resulting from the fit should be approximately equal to 1 per degree of freedom. Based on $s^{2}=9.7 \%$ for the winter and $s^{2}=13.8 \%$ for the summer data, $\chi^{2}$ of 1.03 and 0.99 per degree of freedom result, respectively, indicating an appropriate estimate of variances. From these, no

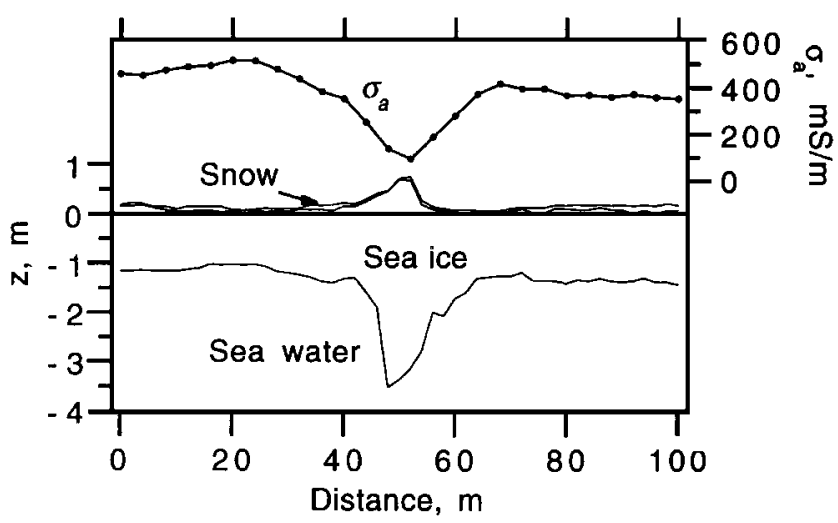

FIG. 2. $100 \mathrm{~m}$ long profiles of snow and ice thickness and apparent conductivity $\sigma_{a}$ as measured in the horizontal dipole mode with the instrument placed on the ice surface (summer, profile S3). The zero line on the left axis marks the sea level. Spacing of drillholes is $2 \mathrm{~m}$; that of $\mathrm{E} M$ measurements is $4 \mathrm{~m}$. 
significant difference between the winter and summer data can be deduced. Pooled winter and summer data result in

$$
\sigma_{a}=62.5+1273.9 \exp \left(-0.915 z_{i}\right)
$$

explaining $98 \%$ of the total variance, $s^{2}$ being $13.6 \%\left(\chi^{2}=\right.$ 0.99).

Inversion of equations $(2 \mathrm{a}),(2 \mathrm{~b})$, and $(2 \mathrm{c})$ yields the transformation equations

$$
\begin{aligned}
z_{i_{w}} & =7.03-\ln \left(\sigma_{a_{w}}-95.8\right) / 0.995 \\
z_{i_{s}} & =7.94-\ln \left(\sigma_{a_{s}}-57.2\right) / 0.900
\end{aligned}
$$

and

$$
z_{i}=7.81-\ln \left(\sigma_{a}-62.5\right) / 0.915 .
$$

A $n$ application of the transformation equation ( $3 b$ ) is presented in Figure $4 a$, showing the $E$ M-derived and drillhole determined ice thickness for the profile of Figure 2. In Figure 4b, the deviation

$$
\delta z_{i}=\left(z_{i_{\mathrm{EM}}}-z_{i_{\text {drill }}}\right) / z_{i_{\text {drill }}} \times 100
$$

of the $\mathrm{E} M$-derived thickness $z_{i_{\mathrm{E}} \mathrm{M}}$ relative to the drilling results $z_{i \text { drill }}$ is presented.

On all profiles, E M -derived and drillhole determined thicknesses match well for winter and summer data. In most cases, the deviations are less than $\pm 10 \%$. O n level ice, characterized by small lateral thickness variations (0-40 $\mathrm{m}$ and 75-100 $\mathrm{m}$ in Figure 2), the accuracy is even better and the deviations seldom exceed $\pm 5 \%$. Thus, over level ice no significant difference occurs between measurements performed in winter and in summer.

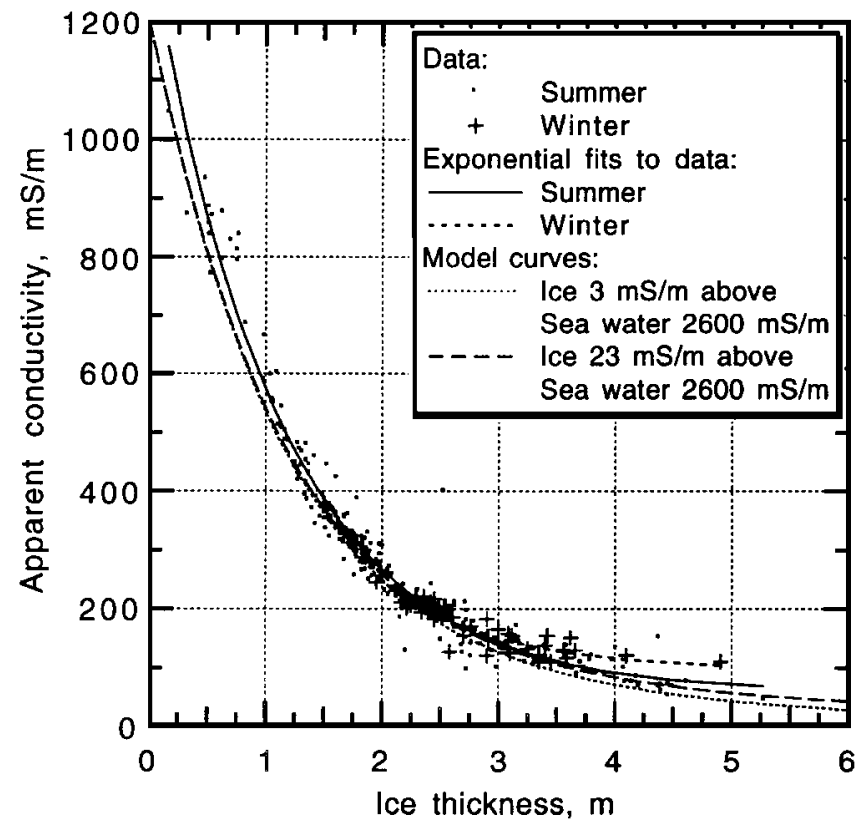

FIG. 3. M easured apparent conductivity versus ice thickness for the complete winter and summer data sets and the exponential fits according to equations (2a) and (2b) for winter and summer data. A Iso plotted are two two-layer 1-D model curves for ice floating on water with a conductivity of $2600 \mathrm{mS} / \mathrm{m}$. I ce conductivities of 3 and $23 \mathrm{mS} / \mathrm{m}$ (see text) have been assumed.
A salso found in all other studies referred to in the Introduction, E M -derived thicknesses differ significantly from drillhole determined thickness only in ridged areas. There, deviations can be as high as $40 \%$.

\section{M elt-pond cross-profiles}

Figure 5 presentsice surface and draft profiles determined by drilling across three melt ponds. A Iso, the E M -derived draft is shown as calculated by means of equation ( $3 b$ ) and by subtraction of the ice freeboard which is zero over melt ponds. While EM and drilling results agree well in Figure $5 a$, the true draft is underestimated in Figure $5 b$, whereas it is overestimated in Figure $5 c$. The pond-water salinity of the ponds shown in Figures $5 \mathrm{a}$ and $5 \mathrm{c}$ was close to zero, but the water of the pond in Figure $5 b$ had a salinity of $17.2 \%$, with a temperature of $-1^{\circ} \mathrm{C}$ resulting in a conductivity of $1473 \mathrm{mS} / \mathrm{m}$. Therefore, the measured apparent conductivity was too high, resulting in an ice-thickness estimate too small compared with the true thickness. In Figure 6, the apparent conductivity from all measurements over melt ponds is plotted versus drillhole determined ice plus melt-water thickness. A s in Figure 3, a negative exponential relationship can be seen. A Iso included in Figure 6 is a model curve for a 2-layer model with a water conductivity of $2600 \mathrm{mS} / \mathrm{m}$ and an ice conductivity of $23 \mathrm{mS} / \mathrm{m}$ resulting from the ice-core analyses below (see also Figure 3 ). This curve explains $84 \%$ of the total variation of the melt-pond data, thus indicating a greater scatter of measurements performed over melt ponds than over pond-free ice. Still, in most cases satisfactory ice plus meltwater thickness values could be derived.

\section{I ce-core analyses}

To yield an estimate of the bulk electric ice conductivity of winter and summer sea ice as input parameters for the 1-D

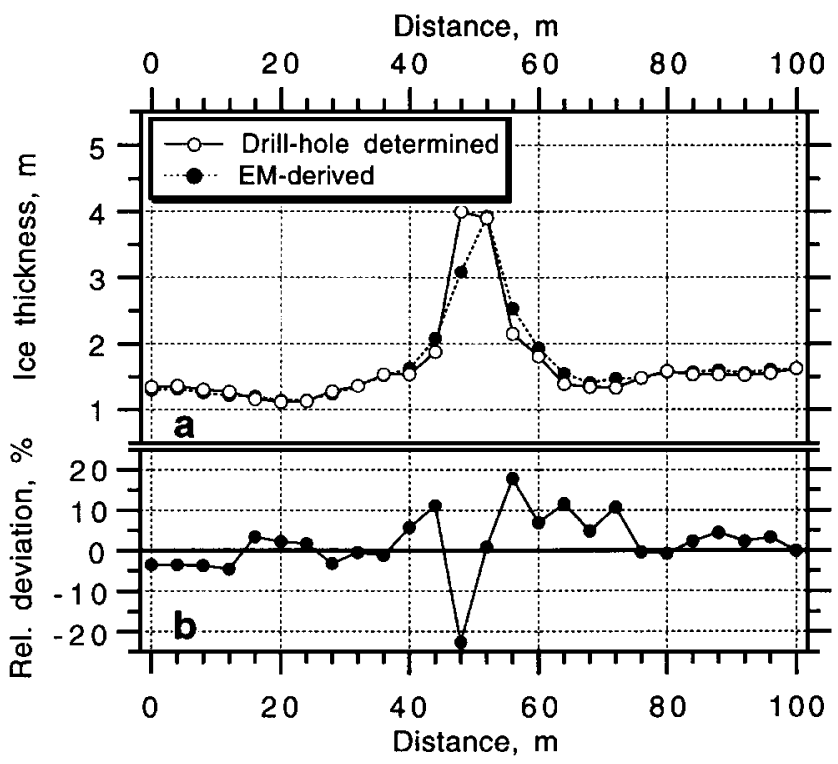

FIG. 4. (a) Ice thickness $z_{i}$ determined from drillholes and by means of equation (3a) along the profile of Figure 2. (b) D eviation $\left(z_{i_{\mathrm{EM}}}-z_{i_{\text {drill }}}\right) / z_{i_{\text {drill }}} \times 100$ between drillhole determined and $\mathrm{E} M$-derived ice thickness in Figure 4a. 
modeling, ice cores were analyzed for values of brine volume. The stratigraphy, microstructure, and salinity profiles of all cores were typical for A rctic multiyear ice (E icken et al., 1995).

For the estimation of relative brine volume, fourth-degree polynomials were fitted to the measured temperatures of the winter cores, and linear temperature profiles from $0^{\circ} \mathrm{C}$ at the top to melting temperatures $\left(-1.8^{\circ} \mathrm{C}\right)$ near the bottom of the ice were assumed for the summer ice cores, consistent with field measurements. R elative brine volumes $V_{b} / V$ were calculated according to Cox and Weeks (1983):

$$
\frac{V_{b}}{V}=\frac{\rho S}{F_{1}(T)},
$$

where $\rho$ and $S$ are the bulk density and salinity of an ice sample and $F_{1}$ is a coefficient dependent on temperature $T$. For temperatures above $-2^{\circ} \mathrm{C}, F_{1}(T)$ was taken from $L$ eppäranta and $M$ anninen (1988). G as volume was assumed to be $10 \%$. In Figure 7, two typical temperature and brine volume profiles are presented for sea-ice cores taken in winter and summer. B ecause of the very low ice temperatures (Figure 7a), brine volumes are very small in winter compared to summer (solid and open symbols, respectively in Figure 7b). M ean brine volume of all cores drilled in winter was $13.6 \%$, and $93.4 \%$ of all

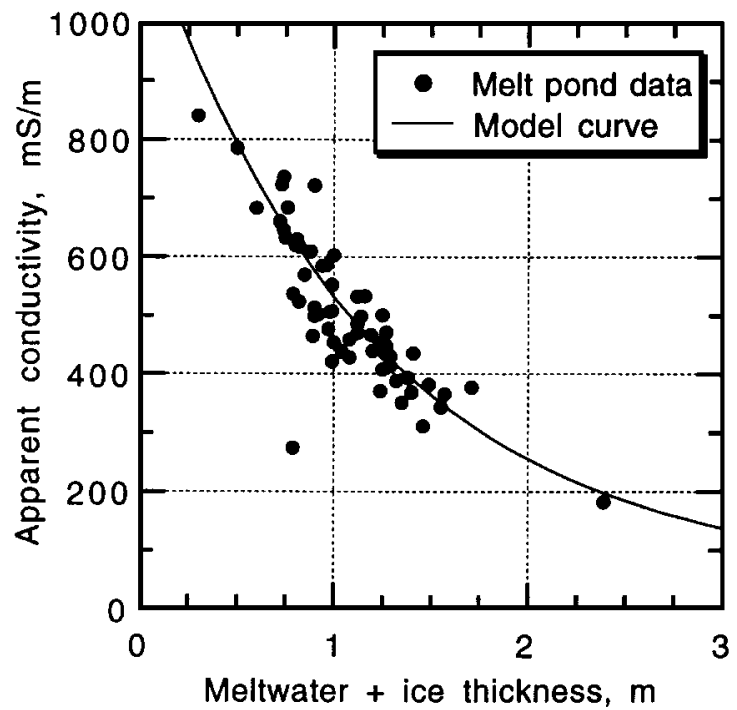

FIG. 6. A pparent conductivity asmeasured in horizontal dipole mode with the instrument placed immediately above the surface of melt ponds versus meltwater plusice thickness. The solid line is a 1-D model curve for salinities of 23 and $2600 \mathrm{mS} / \mathrm{m}$ for ice and sea water, respectively (cf., Figure 3).

a)

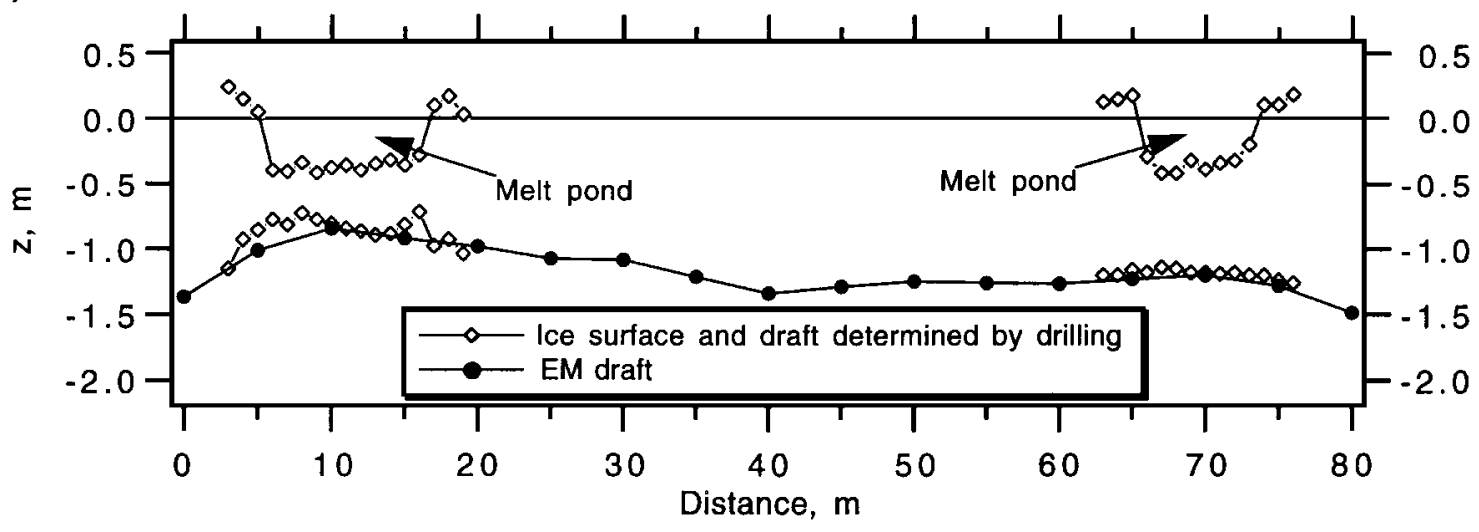

b)

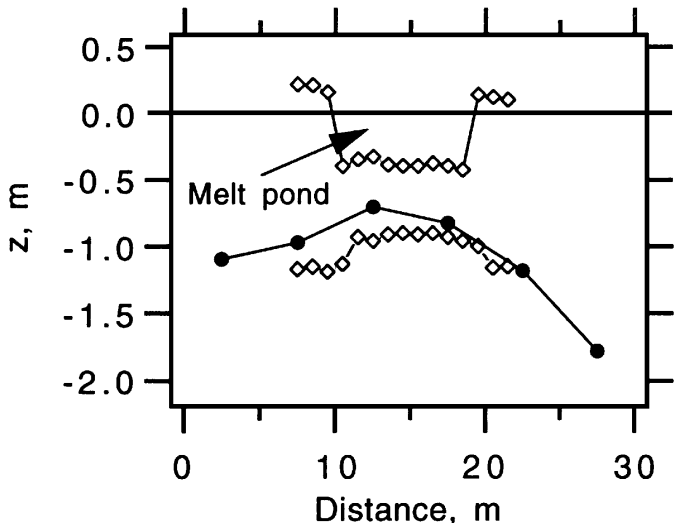

c)

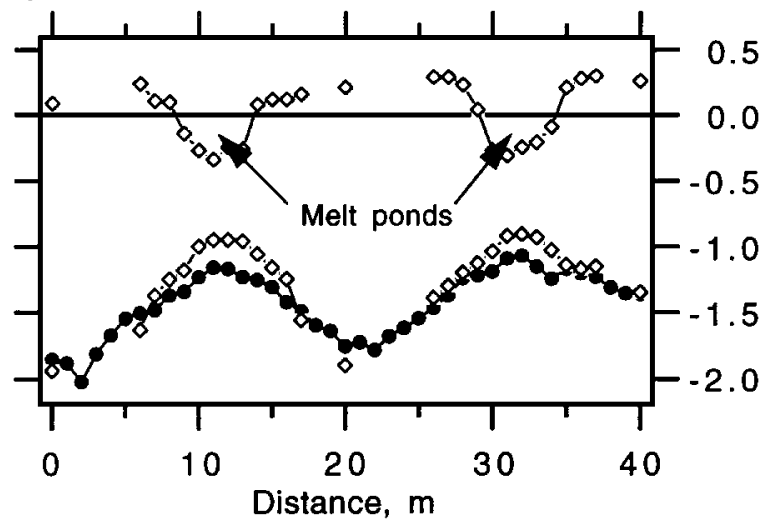

FIG. 5. M elt pond cross-profiles as determined by drillhole and EM measurements. The EM draft was calculated by means of equation (3a) and subtraction of ice freeboard which is zero over melt ponds because the pond surface is at sea level ( $z=0)$. 
summer cores, the latter value being slightly smaller than mean brine volumes of summer multiyear ice in the E urasian sector of the $\mathrm{A}$ rctic $\mathrm{O}$ cean found in $\mathrm{E}$ icken et al. (1995), which ranged from 100 to $150 \%$.

To calculate bulk ice conductivities from the measured temperatures and brine volumes, we followed a procedure suggested in M orey et al. (1984) and Kovacs and M orey (1988). It takes into account that sea ice is a mixture of pure ice and brine. While the pure ice fraction is considered to be nonconducting, the temperature-dependent conductivity $\sigma_{b}$ of the brine is given by (Stogryn and D esargant, 1985)

$$
\sigma_{b}=-T \exp (0.5193+0.08755 T) ; \quad T \geq-22.9^{\circ} \mathrm{C}
$$

and

$$
\sigma_{b}=-T \exp (1.0334+0.11 T) ; \quad T<-22.9^{\circ} \mathrm{C} .
$$

A relationship between the conductivity $\sigma_{i}$ of brine-saturated media and their porosity $\Phi$ is given by the empirical A rchie's law (A rchie, 1942)

$$
\sigma_{i}=\sigma_{b} \Phi^{m}
$$

where $m$ is an empirical constant ("cementation factor"). O riginally, this expression was derived for permeable sandstones displaying no preferred shape or orientation of pores. For $m$, M orey et al. (1984) derived values between 1.55 in the top and 1.75 near the bottom of the ice, while Thyssen et al. (1974) found a value of 2.2. In our calculations, we choose $m=1.75$.

Sea-ice conduction is believed to occur mainly in vertically aligned brine channels and the porosity is smaller than in most sandstones. However, since a comprehensive theory of conduction processes in sea ice is highly involved, A rchie's law provides a first estimate of sea-ice conductivity.

Conductivity profiles were calculated for all coresas outlined above. This resulted in a mean ice conductivity of $3 \mathrm{mS} / \mathrm{m}$ for a)

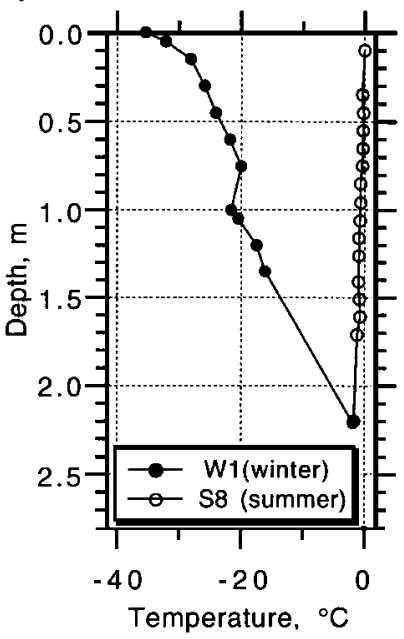

b)

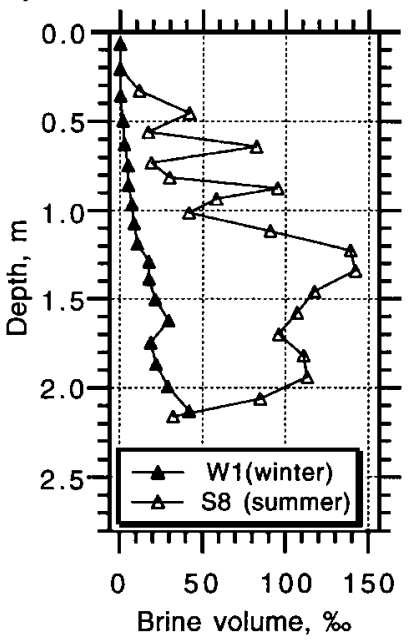

FIG. 7. Temperature (a) and brine volume (b) profiles of two typical multiyear ice cores obtained during A R K -IX/1a (from profile W 1 , solid symbols) and A RK-IX/4 (from profile S8, open symbols). the winter cores and $23 \mathrm{mS} / \mathrm{m}$ for the summer cores, respectively.

The results of the 1-D modeling using these two values as conductivities for the ice are also included in Figure 3. A s in the measurements, apparent conductivity decreases exponentially with increasing ice thickness. The effect of the different ice conductivities is rather small, getting larger with increasing ice thickness, as more and more ice is contained in the region sensed by the instrument. B oth curves provide a sufficient fit to the data at small and intermediate ice thicknesses.

\section{DISCUSSION}

\section{Validity of transformation equations}

E quations ( $3 a),(3 b)$, and ( $3 c$ ) are empirical relations, which implies that they are only valid for conditions similar to those for which the underlying data set was obtained. H owever, the ice-core results demonstrate that the state of the ice cover during both surveys was representative of A rctic multiyear pack ice during seasonal extremes. Hence, equation (3a) may be used for most A rctic multiyear ice at very low temperatures, while equation ( $3 \mathrm{~b}$ ) is valid for A rctic multiyear ice in summer, or equation (3c) could be used for all data. Furthermore, the transformations are only valid within certain thickness limits. Strictly, they can only be used for the thickness and conductivity range covered by the underlying data set. Further data are required for larger thicknesses, although here the problem of the 3-D nature of the measurements enters, because larger thicknesses are most likely to occur in deep draft pressure ridges.

A nother estimate for the range in which reliable measurements could be performed is provided by the slope of the curves in Figure 3 and equations (2), respectively, since they reflect the dynamic response of the instrument with respect to ice thickness variations. Thus, to resolve a change in thickness of $0.1 \mathrm{~m}$, the gradient of the curves should be larger than $2 \mathrm{mS} / \mathrm{m}$ per $0.1 \mathrm{~m}$ thickness variation, if the instrument reading is taken to be stable within $\pm 2 \mathrm{mS} / \mathrm{m}$ (which from our experience is a reasonable assumption). This is achieved for thicknesses less than about $4 \mathrm{~m}$ and $4.5 \mathrm{~m}$ for the winter and summer data, respectively, and for less than $5 \mathrm{~m}$ for the 1-D model curves. For comparison, the theoretical 1-D sensitivity of measurements carried out in the vertical dipole mode is slightly better, being sufficient for thicknesses of up to $5.6 \mathrm{~m}$ (curves not shown here). To extend the thickness range of $\mathrm{E} M$ measurements, an instrument with a better signal-to-noise ratio or a wider coil spacing has to be used, although this would reduce the lateral resolution.

It should be noted that equations (3) were derived from real data gathered over both level as well as thicker deformed ice (see also below), even though the method was shown to be less reliable over the latter. If it were surely known in advance that the ice was level and undisturbed, then a transformation equation could have been used derived by inversion of a fit to a 1-D model curve. For example, fitting an exponential function to the $23 \mathrm{mS} / \mathrm{m}$ curve in Figure 3 in the 0 to $5 \mathrm{~m}$ thickness range would yield a transformation equation

$$
z_{i}=8.38-\ln \left(\sigma_{a}-43.3\right) / 0.842
$$

( $r=1.0)$ which would result in the most accurate thickness interpretations of level ice, much better than by use of 
equation (3). But the problem is that in many cases the ice cannot be assumed to be level and undeformed in advance, equations (3) thus being better choices for the general case of measurements in the field.

This discussion shows that from a different point of view, the problem of accuracy of the EM measurements can be considered as the problem of identifying whether a stretch of sea ice is level or deviates from an ideal one-layer case. To meet this problem fully, a multifrequency instrument would be needed, allowing to reduce the ambiguities inherent to the use of a single-frequency instrument only.

\section{Comparison of E M-derived and drillhole determined thickness}

Table 1 lists mean EM-derived and drillhole determined thicknesses $\bar{z}_{i_{\mathrm{EM}}}$ and $\bar{z}_{i_{\text {drill }}}$ for all 12 profiles along with their standard deviations $s_{\mathrm{EM}}$ and $s_{\text {drill }}$. A dditionally, the deviations between the means $\bar{z}_{i_{\mathrm{EM}}}$ and $\bar{z}_{i_{\text {drill }}}$ are presented. A Ithough measurements at individual points in the region of pressure ridges can deviate largely, these deviations almost seem to vanish if mean values for complete profiles and in particular across pressure ridges are considered. A pparently, the positive deviations at ridge flanks effectively compensate the negative deviations over ridge crests (Figure 4). Still, the largest deviations occur for profiles S1 and S10, which also exhibit the largest standard deviations, corresponding to a rough thickness profile. Further, $s_{\mathrm{EM}}$ is strongly correlated with $s_{\text {drill }}(r=0.97$, Table 1), showing that EM profiles across rough ice do not generally appear smoothed. This is also a result of thickness variations perpendicular to the profile direction that are not at all represented in the drilling data.

The problems encountered in deformed ice are also reflected in the deviations between model curves and the exponential fits to the data at ice thicknesses bigger than 3 to $4 \mathrm{~m}$ in Figure 3. Since the model curves have been calculated with a 1-D model, they give the expected apparent conductivity at a certain thickness of a level, infinitely extended plate of ice. In contrast, the data presented in Figure 3 have been measured on both level and deformed ice, the larger thicknesses almost entirely caused by measurements over pressure ridges. Here, as a result of the areal averaging of the subsurface conductivity, the determined apparent conductivity is higher than in the case of level ice of the same thickness.

\section{M easurements on summer sea ice}

The extreme differences in general physical properties of winter and summer sea ice are only of minor importance for ice conductivity, introducing little difference between winter and summer data and the model curves in Figure 3. Still, although this difference is not significant, the apparent conductivities over ice of intermediate thickness ( 1 to $2.5 \mathrm{~m}$ ) measured in winter are smaller than in summer, indicating lower ice conductivities. The model results emphasize that at both seasonal extremes EM measurements are a suitable tool to determine ice thickness. That this is also true for measurements in summer is because of the properties of the meltwater. A Ithough brine volumes of summer sea ice are much higher than in winter, the brine and meltwater filling the pores have only low salinities, because brine and ice generally are in a phase equilibrium, and warm ice cannot coexist with high salinity brine. For example, average brine salinities of typical multiyear ice in summer as directly measured by Eicken et al. (1995) range from $4.8 \%$ in the top to $16.7 \%$ in the lower parts of the ice column, i.e., are much smaller than seawater salinity. Thus, the resulting ice conductivity of $23 \mathrm{mS} / \mathrm{m}$ derived here is only slightly greater than the $3 \mathrm{mS} / \mathrm{m}$ for the winter ice, making the summer ice transparent for the EM dipole fields. Since the conductivity contrast between the ice and seawater remains very large, the E M measurements are not altered significantly.

The seasonal differences between physical properties of the ice are mainly caused by different ice temperatures at the respective time of the year. To investigate the effect of temperature on the electrical conductivity profile within A rctic multiyear ice with a typical mean salinity profile [calculated from 66 cores by Eicken et al. (1995)], we calculated ice conductivity profiles for surface temperatures of $0,-1.8,-10,-20$, -30 , and $-40^{\circ} \mathrm{C}$, assuming a linear temperature profile from the top to the bottom, the latter taken to be at the melting temperature of $-1.8^{\circ} \mathrm{C}$ (Figure 8a). The complete range of seasonal extremes is covered by these values. I ce conductivities for each depth interval ( $0.01 \mathrm{~m}$ resolution) were calculated as described above (Figure $8 \mathrm{c}$ ). Since the bottom temperature is the same for all profiles, differences mainly occur in the middle and top portions of the profiles. Ice conductivities are highest for the $0^{\circ} \mathrm{C}$-surface-temperature profile and lowest for the $-40^{\circ} \mathrm{C}$ profile. It is important to note that the largest differences occur between the 0 and $-1.8^{\circ} \mathrm{C}$ profiles, while below surface temperatures of $-10^{\circ} \mathrm{C}$ ice conductivity does not vary much. Thus, ice properties relevant for the $\mathrm{E} M$ measurements vary little throughout most seasons and change only significantly during summer. Still, as outlined above, the EM measurements are hardly affected in any season. A part from brine volume, brine conductivity also enters into the calculation of ice conductivity according to equation (7). B rine conductivity profiles for the respective surface temperatures calculated from equations (6) are plotted in Figure 8b. G enerally, as brine temperature decreases, brine salinity increases. This leads to increasing brine conductivity only down to a temperature of $-11.4^{\circ} \mathrm{C}$. B elow this temperature, ion mobility in the brine is reduced and therefore its conductivity decreases with temperature. For ice conductivity this implies that decreasing brine volume due to decreasing temperature is compensated by increasing brine conductivity, but only down to $-11.4^{\circ} \mathrm{C}$. B elow this temperature, both brine volume and brine conductivity cause reduced ice conductivity.

Similar to the ice, in most cases melt ponds were found to be transparent for the $\mathrm{E} M$ fields, since their water is derived from the melting of snow and low-salinity upper icelayers (Figure 7). For example, water samples obtained from a larger number of surface melt ponds by E icken et al. (1994) had a mean salinitiy of $2.9 \%$, with a broad maximum of the distribution at about 0.5 to $1 \%$, resulting in very small conductivities. Therefore, the total thickness of the ice plus meltwater layer is correctly determined. N evertheless, the melt-pond measurements show a larger scatter than measurements over pond-free ice (Figures 3 and 6). This, on the one hand, is caused by the fact that melt ponds may in some cases exhibit higher salinities approaching those of seawater (E icken et al., 1994). O n the other hand, the scatter of the pond data is more likely due to the fact that the ice bottom topography below ponds often is vaulted upward (like in the extreme example in Figure $5 c$ ), as a result of enhanced 
melting caused by higher energy absorption within the lowalbedo ponds. These morphological features affect measurements in the same way as ridges do.

$O$ ther common features occurring in summer are melt-water lenses or under-ice melt ponds forming underneath the ice as a result of meltwater runoff at floe edges or downward percolation of meltwater (Wadhams and M artin, 1990; E icken, 1994). Typically, the thickness of these lenses ranges from a few centimeters to a few decimeters. B ecause the density of meltwater is lower than that of the seawater, it tends to collect at the ice bottom, in particular within depressions such as are often found beneath surface melt ponds. Since the meltwater ishighly transparent to the $\mathrm{EM}$ fields, ice thickness is overestimated in such cases (as may be the case in Figure $5 c$ ). H owever, since much of the meltwater entrapped underneath the ice freezes due to the contact with the cold seawater even during summer (E icken, 1994), this meltwater could still be considered as part of the ice cover, being only temporarily in a fluid phase. The problem with under-ice meltwater lenses is that their presence generally cannot be predicted.

\section{CONCLUSIONS}

The results shown demonstrate that the small-offset looploop E M technique can be applied successfully for the indirect determination of level sea-ice thickness, extending the previous work conducted in the North A merican A rctic under winter and spring conditions (Kovacs and H olladay, 1990; K ovacs and M orey, 1991) to the E urasian A rctic and to the summer season. Comparison of winter and summer data bracketing the most extreme conditions to be encountered during measurement campaigns in conjunction with ice-core studies demonstrated the robustness and general applicability of the technique.
M elt season conditions with their fundamental differences in physical sea-ice properties introduce greater scatter into the ice-thickness versusapparent conductivity relation, because ice conductivity can vary in greater ranges than in winter. Surface melt ponds typical for A rctic summer sea ice are almost transparent for the $\mathrm{E} M$ fields and allow ice plus meltwater thickness to be determined correctly in most cases. U nder-ice melt ponds, where they exist, generally result in overestimates of ice thickness of some centimeters to one or two decimeters. This could be a concern for engineering applications of ice-thickness measurements.

The study showed that for level and moderately deformed ice, empirical conductivity-thickness relations may provide reliable, readily available ice-thickness estimates. M oreover, the study showed that these relations also hold for summer sea ice even in areas of melt ponds.

A lthough for greater ice thicknesses observed in pressure ridges the accuracy of the $\mathrm{E} M$-derived thickness decreases significantly and may be rather poor, the technique does at least provide valuable data on the distribution and typical length scale of such thick or deformed ice. These are important variables for the validation of sea-ice models ( $\mathrm{H}$ arder and L emke, 1994).

Measurements presented here, like those of Kovacs and M orey (1991), were performed with a portable small-offset loop-loop instrument. O perated during station times of icebreaking research vessels cruising through ice-covered regions, these measurements can yield representative data on the regional thickness distribution. Furthermore, the results of this study with respect to measurements over summer sea ice also apply to airborne EM surveys, which can operate much more effectively.
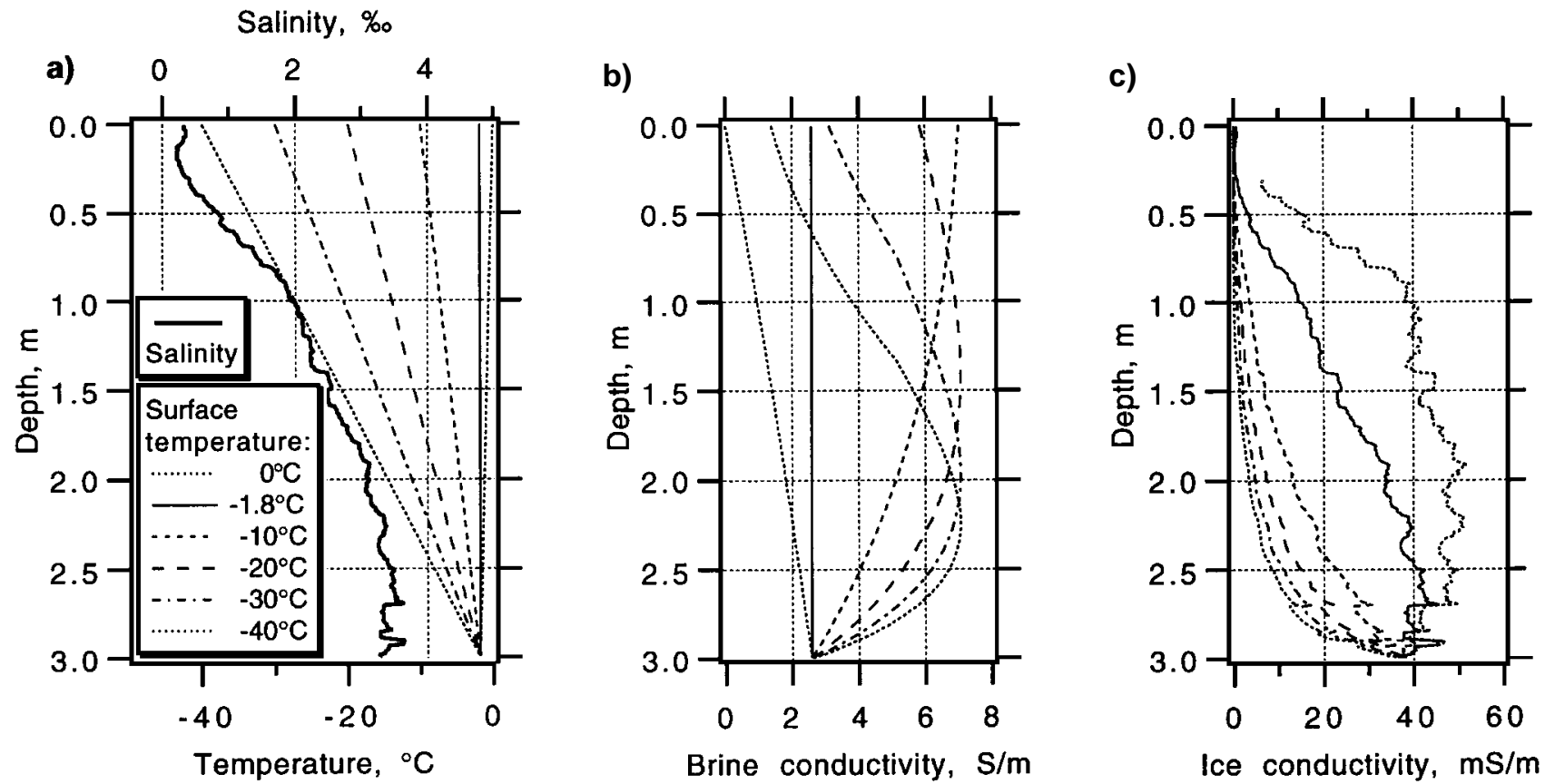

FIG. 8. Profiles of mean salinity (a; top axis, thick line; see text) and different temperatures (a; bottom axis, thin lines) used as input for the calculation of profiles of electrical brine ( $b$; only dependent on temperature) and ice conductivity $(c)$. The air-temperature legend of $(a)$ is also valid for the curves in (b) and (c). 


\section{ACKNOWLEDGMENTS}

S. H annke, R. Pac, E . R eimnitz, D. N. Thomas, and F. Valero are gratefully acknowledged for indefatigably drilling holes into the ice. Without the support of captain and crew of RV Polarstern it would not have been possible to obtain the data for this paper. Suggestions by S. A rcone considerably improved the manuscript. This is A WI publication no. 919.

\section{REFERENCES}

A nderson, W. L., 1979, Computer Program. Numerical integration of related $\mathrm{H}$ ankel transforms of orders 0 and 1 by adaptive digital filtering: $\mathrm{G}$ eophysics, 44, 1287-1305.

A rchie, G. E ., 1942, The electrical resistivity log as an aid in determining some reservoir characteristics: Trans., A m. Inst. M in., M etall., Petr. Eng., 146, 54-62.

Coachman, L. K., and A agaard, K., 1974, Physical oceanography of A rctic and subarctic seas, in $\mathrm{H}$ erman, $\mathrm{Y}$., $\mathrm{E} \mathrm{d}$., $\mathrm{M}$ arine $\mathrm{G}$ eology and 0 ceanography of the A rctic seas: Springer-Verlag, 1-72.

Cox, G. F. N., and Weeks, W. F., 1983, E quations for determining the gas and brine volumes in sea-ice samples: J. G laciol., 29, 306-316.

E icken, H ., 1994, Structure of under-ice melt ponds in the central A rctic and their effect on the sea ice cover: $L$ imnol. O ceanogr., 39, 682-694.

Eicken, H., A lexandrov, V., G radinger, R., Ilyin, G., Ivanov, B., L uchetta, A ., M artin, T., O Isson, K ., R eimnitz, E ., Pac, R ., Poniz, P., and Weissenberger J., 1994, D istribution, structure and hydrography of surface melt puddles, in Fütterer, D. K., E d., The expedition A R CTIC '93, leg A R K -IX/4 of RV "Polarstern" in 1993: R eports on Polar R esearch, 149, 73-76.

E icken, H., Lensu, M ., L eppäranta, M ., Tucker III, W. B., G ow, A . J., and Salmela, O., 1995, Thickness, structure and properties of level summer multi-year ice in the E urasian Sector of the A rctic O cean: J. G eophys. R es., 100, 22,697-22,710.

$\mathrm{H}$ arder, M ., and Lemke, P., 1994, M odelling the extent of sea ice ridging in the Weddell Sea, in J ohannessen, O. M., M uench, R. D., and O verland, J. E., Eds., The polar oceans and their role in shaping the global environment: A m. G eophys. U nion, G eophys. M ono. 85, 187-197.

H oekstra, P., 1980, Theoretical and experimental results of measurements with horizontal magnetic dipoles over sea water to measure ice thickness and water salinity: G eo-Physi-C on C $0 ., \mathrm{L}$ td (unpublished manuscript).

K eller, G. V., and Frischknecht, F. C., 1966, E lectrical methods in geophysical prospecting: Pergamon Press, Inc.

Kovacs, A., and Holladay, J. S., 1990, Sea-ice thickness measurements using a small airborne electromagnetic sounding system: $G$ eophysics, 55, 1327-1337.

Kovacs, A., H olladay, J. S., and Bergeron, C. J., J r., 1995, The footprint/altitude ratio for helicopter electromagnetic sounding of seaice thickness: Comparison of theoretical and field estimates: $\mathrm{Geo-}$ physics, 60, 374-380.
Kovacs, A ., and M orey, R. M., 1988, Electromagnetic measurements of a second year sea ice floe, in Sackinger, W. M., and I effries, M. O. E ds., Port and ocean engineering under arctic conditions: POA C, 1, 121-136

- - - 1991, Sounding sea-ice thickness using a portable electromagnetic induction instrument: $\mathrm{G}$ eophysics, 56, 1992-1998.

Kovacs, A ., Valleau, N. C., and H olladay, J. C., 1987, A irborne electromagnetic sounding of sea-ice thickness and subice bathymetry: Cold R egions Sci. and Tech., 14, 289-311.

L eppäranta, M ., and M anninen, T., 1988, The brine and gas content of sea ice with attention to low salinities and high temperatures: Finnish Institute of $M$ arine R esearch, Internal R eport 2.

Liu, G., and Becker, A., 1990, Two-dimensional mapping of sea-ice keels with airborne electromagnetics: G eophysics, 55, 239-248.

L iu, G., K ovacs, A ., and B ecker, A ., 1991, Inversion of airborne electromagnetic survey data for sea-ice keel shape: G eophysics, 56, 19861991.

Maykut, G. A., 1986, The surface heat and mass balance, in U ntersteiner, N., Ed., The geophysics of sea ice: Plenum, 395463.

M itchell, J. F. B., M anabe, S., M eleshko, V., and Tokioka, T., 1990, Equilibrium climate change and its implications for the future, in H oughton, J. T., J enkins, G. J., and E phraums, J. J., E ds., Climate change-the IPCC scientific assessment: Cambridge U niv. Press, 131-172.

Morey, R. M., Kovacs, A ., and Cox, G. F. N., 1984, Electromagnetic properties of sea ice: CRR EL M onogr., 84-2.

M ultala, J., H autaniemi, H ., O ksama, M ., L eppäranta, M ., H aapala, J., H erlevi, A ., R iska, K ., and L ensu, M ., 1995, A irborne electromagnetic surveying of baltic sea ice: $R$ eport series in $G$ eophysics, $U$ niv. of $\mathrm{H}$ elsinki, D ept. of G eophysics, 31.

Sinha, A . K., 1976, A field study for sea ice thickness determination by electromagnetic means: G eol. Surv. of Canada, G SC Paper 76-1C 225-228.

Stogryn, A ., and Desargant, G. J., 1985, The dielectric properties of brine in sea ice at microwave frequencies: IE E E Trans. on A ntennas and Propagation, A P-33, 523-532.

Thyssen, F., Kohnen, H. Cowan, M. V., and Timco, G. W., 1974, D C resistivity measurements on the sea ice near Pond I nlet, N.W.T (B affin Island): Polarforschung, 44, 117-126.

U NESCO 1983, A lgorithms for computation of fundamental properties of sea water: U nesco Tech. Pap. in M ar. Sci., 44.

Wadhams, P., and M artin, S., 1990, Processes determining the bottom topography of multiyear A rctic sea ice, in Weeks, W. F., and A ckley, S. F., E ds., Sea ice properties and processes: CR R E L M onogr. 90-1, 136-141.

Wadhams, P., Tucker III, W. B., K rabill, W. B., Swift, R. N., Comiso, J $C$., and $D$ avis, N. R ., 1992, R elationship between sea ice freeboard and draft in the $A$ rctic B asin, and implications for ice thickness monitoring: J. G eophys. R es., 97, 20,325-20,334.

Ward, S. H., and Hohmann, G. W., 1988, Electromagnetic theory for geophysical applications, in N abighian, M. N., E d., E lectromagnetic methods in applied geophysics-theory, volume 1: Soc. Expl. G eophys. M onograph, 3, 131-313. 